\title{
Sex-dependent Depot Differences in Adipose Tissue Development and Function; Role of Sex Steroids
}

\author{
Mi-Jeong Lee*, Susan K. Fried \\ Diabetes Obesity \& Metabolism Institute, Icahn School of Medicine at Mount Sinai, New York, USA
}

Men and women are different in their fat mass and distribution pattern. The gynoid-type fat distribution, accumulation in lower-body, is considered to be protective while the android-type accumulation in upper-body, both in abdominal subcutaneous and visceral depots, is detrimental. Sex-dependent depot differences in adipose metabolic and endocrine functions are thought to contribute to the sexual disparity in fat distribution as well as its association with cardiometabolic risks. Although molecular details have not been completely elucidated, available evidence shows that sex steroid hormones are important factors governing sexual dimorphism in adipose tissue distribution and hence, risks for metabolic diseases. We will review sex-dependent heterogeneities in adipose tissue properties that can link their depot-specific biology to metabolic complications in men and women. In addition, we will also review how sex steroids regulate adipose tissue biology, both development and functional characteristics, with emphasis on their depot-dependent actions.

Key words: Estrogen, Androgen, Fat distribution, Adipocyte biology

\author{
Received July 21, 2017 \\ Reviewed August 20, 2017 \\ Accepted August 28, 2017 \\ *Corresponding author \\ Mi-Jeong Lee \\ (iD) \\ http://orcid.org/0000-0002-8171-7913 \\ Diabetes Obesity \& Metabolism \\ Institute, Icahn School of Medicine at \\ Mount Sinai, 1 Gustave Levy Place, Box \\ 1152, New York, NY 10029, USA \\ Tel: +1-212-241-7315 \\ Fax: +1-212-241-7315 \\ E-mail: mi-jeong.lee1@mssm.edu
}

\section{INTRODUCTION}

Obesity, defined as excess of adipose tissue, is increasing worldwide. Obese individuals have higher risk of developing multiple cardiometabolic diseases including insulin resistance, type 2 diabetes, cardiovascular diseases and several types of cancer. Mammals contain numerous anatomically distinct adipose depots and disparities in the developmental origin, metabolic and endocrine function and remodeling capacity of each depot have been appreciated. Over and above total adiposity per se, fat distribution pattern influences systemic metabolism and female-type fat distribution is considered to be healthier. Although factors that govern this sexual dimorphism are not completely elucidated, much attention has been paid to the role of sex steroid hormones, estrogen and androgens. In addition, both genetic (e.g. presence of the $\mathrm{X}$ and $\mathrm{Y}$ chromo- some) and epigenetic events modulate the actions of sex steroids in adipose tissue through both central and peripheral actions.

\section{Adipose tissues}

Different sizes and shades (white, brown and beige) of adipose tissues are present in multiple locations throughout an organism. White adipose tissues (WAT) are divided into subcutaneous adipose tissue (SAT) which underlies the skin and visceral adipose tissue (VAT) which is inside of intraabdominal cavity in association with the internal organs. ${ }^{1}$ The major SATs in humans are the abdominal, gluteal and femoral and intraabdominal depots are omental (hangs off the stomach), mesenteric (associated with the intestine), epiploic (along the colon) and epicardial (around heart). Adult humans also contain brown adipose tissue (BAT) as well as inducible brown, brite/beige adipose tissues. Brown and brite/

Copyright @ 2017 Korean Society for the Study of Obesity

(a) This is an Open Access article distributed under the terms of the Creative Commons Attribution Non-Commercial License (http://creativecommons.org/licenses/by-nc/4.o/) which permits unrestricted non-commercial use, distribution, and reproduction in any medium, provided the original work is properly cited. 
beige compared to white adipocytes contain more mitochondria and express uncoupling protein 1 (UCP1) and hence, they are thermogenetically more active and dissipate energy as heat. Intense research is going on whether increasing BAT and brite/beige adipocytes has beneficial effects, improving metabolic complications and reducing body weight. ${ }^{2}$ Each adipose depot differs in their cellular compositions and physiology which affect their metabolic and endocrine properties and their influence on systemic health. ${ }^{1}$

\section{Female type fat distribution is associated with lower risk} of developing cardiometabolic diseases

It is well known that women and men differ in fatness. Women generally have higher fat mass than men; women with body mass indexes (BMI) of $20-25 \mathrm{~kg} / \mathrm{m}^{2}$ contain $25-30 \%$ body fat, while men with the same BMI have 10-20\% body fat. ${ }^{3}$ In addition, premenopausal women are characterized by less VAT and more fat accumulation in the lower body, gluteal-femoral region, whereas men accumulate more fat in the central regions, both abdominal subcutaneous and visceral fat (Fig. 1). The reasons why women have more fat mass and preferential accumulation in the femoral-gluteal region is not known, but one hypothesis posits that women reserve more energy in preparation for reproduction and lactation. ${ }^{4}$ Nevertheless, these sexual-dimorphisms in fat distribution are thought to help explaining men having greater risks of developing cardiometabolic diseases than premenopausal women. ${ }^{5}$

In addition to the differences in total mass and distribution pattern in WAT, women have higher amount and activity of BAT than

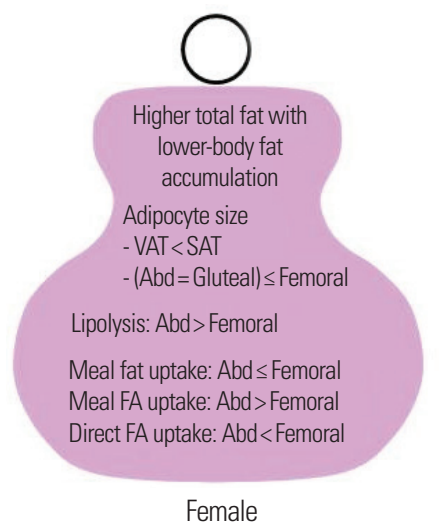

Female

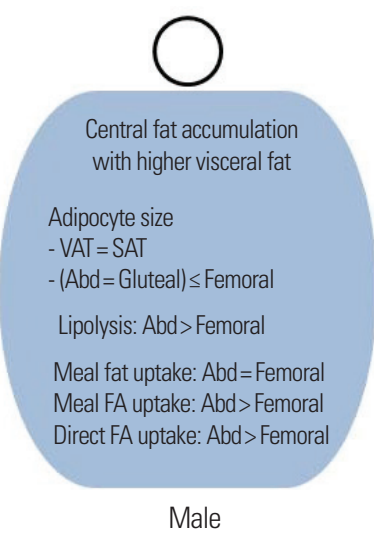

Figure 1. Sexual dimorphism in fat distribution and adipose tissue biology. VAT, visceral adipose tissue; SAT, subcutaneous adipose tissue; Abd, abdominal; FA, fatty acid. men. ${ }^{6}$ Expression levels of mitochondrial genes and UCP1 in SAT are also reported to be higher in women than $\mathrm{men}^{7}$, suggesting that women have more brite/beige adipocytes in their SAT. In addition, women compared to men have higher potency to gain BAT-like properties in perirenal adipose tissue. ${ }^{8}$ Women are more sensitive to cold ${ }^{8}$ and this is likely to explain the higher beige and brown fat activity in women. Whether these sexual dimorphisms in brown and brite adipose tissue amount contribute the lower risk of metabolic diseases in women is not known.

\section{Depot-differences in adipose cellularity and remodeling capacity: potential sexual dimorphism in adipose expansion capacity}

Adipocytes constitute most of the volume in adipose tissues and the size of a fat depot is determined by both the number and size of adipocytes. Adipocyte number is regulated by the balance of new fat cell formation (adipogenesis) and death of existing adipocytes and the size of adipocytes is determined by the amount of lipid stored, which in turn is regulated by the balance of storage and breakdown of lipid. Sex-dependent depot differences in the number and size of adipocytes have been reported (Fig. 1). Adipocyte size is greater in abdominal subcutaneous than visceral in women, while they are similar in size in men and extremely obese women. ${ }^{1}$ Adipocyte size is generally bigger in femoral than abdominal and similar between abdominal and gluteal adipose tissues in both sexes.

Adipose tissue expansion during normal growth and in response to energy excess occurs by increasing the number (hyperplasia) and/or size (hypertrophy) of adipocytes. Hyperplastic growth is considered to be healthier while hypertrophic expansion leads to adipocyte death and high inflammation. Studies in rodent models suggest that sex-dependent depot differences in remodeling capacity through hyperplasia vs. hypertrophy impacts systemic metabolism. In response to energy excess, male gonadal depot grows mainly through hypertrophy, while female gonadal and subcutaneous depots in both sexes expand through both hypertrophy and hyperplasia. ${ }^{9,10}$ As a result, adipocyte death and inflammation is much less in the gonadal depot from female compared to male mice and age-matched female mice are far less susceptible to insulin resistance caused by high fat diet-induced obesity, 9,10

Similar to the results from rodent studies, a study indicates that 
hyperplasia is more predominant in subcutaneous than omental depot, while adipocyte hypertrophy is observed both in omental and subcutaneous depots of obese women. ${ }^{11}$ Numbers of preadipocytes as well as their adipogenic capacity is reported to be higher in subcutaneous than omental human adipose tissues ${ }^{12}$, which may contribute to the hyperplasia in the subcutaneous depot. Higher adipocyte death and inflammation in visceral than subcutaneous depots have been reported in humans ${ }^{13,14}$, supporting the hypothesis that expansion through hyperplasia is healthier. Sex-dependent depot differences between visceral and subcutaneous depots in adipose expansion capacity and their contribution to systemic metabolism in humans are not known.

The number of adipocytes in both upper and lower body subcutaneous fat increases significantly by BMI category in women, but not in men. ${ }^{15}$ Further, a recent study showed that fat cell size is bigger in men than women, while fat cell number is greater in women than men in the abdominal depot of non-obese subjects. ${ }^{16}$ These results suggest that abdominal fat expansion is more hypertrophic and less hyperplastic in men than women in non-obese subjects. In addition, it has been reported that depot difference in the number of adipocytes between lower and upper body fat diminishes with increasing $\mathrm{BMI}$ in men but become more pronounced in women ${ }^{16}$, implying preferential hyperplastic expansion in the lower body depot of women with increasing degree of obesity. Similarly, Tchoukalova et al. ${ }^{17}$ reported that premenopausal women compared to men have a greater number of early differentiated adipocytes specifically in the femoral than abdominal depot.
Only few studies have measured depot differences in adipocyte kinetics in vivo. The rates of adipose stem cell and adipocyte formation in vivo are reported to be higher in the femoral compared to abdominal depots ${ }^{18}$ and after 8 -week overfeeding, the rates of adipocyte formation is higher in the femoral than abdominal subcutaneous. ${ }^{19}$ Thus, available data suggest that the rates of adipocyte generation are higher in the lower body than upper body subcutaneous depot. Whether these depot differences in adipocyte kinetics differ between women and men are not known.

\section{Role of sex steroid hormones in adipose tissue development}

Sex-dependent differences in fat mass and distribution are observed as early as in puberty and age-related decline in sex steroids in humans is associated with more fat accumulation in central regions, indicating the importance of sex steroid hormones in adipose tissue development and distribution. Other factors are also important and Chen et al. ${ }^{20}$ reported that the number of $\mathrm{X}$ chromosomes as well as $\mathrm{Y}$ chromosome, independent of sex steroid hormones, affects adiposity and metabolism in mice. The effects of sex steroids on adipocyte development and function have been investigated in both in vitro cell culture models and in vivo studies using gonadectomy and replacement/supplementation of hormones (Table 1). Sex steroids mediate their biological actions through their nuclear receptors, estrogen receptor (ER) and androgen receptor (AR), and knockout and overexpression transgenic models have been generated to understand the molecular details of

Table 1. Sex steroid regulation of adipose biology

\begin{tabular}{|c|c|c|}
\hline & Estrogen & Androgen \\
\hline \multicolumn{3}{|l|}{ Adipose development } \\
\hline Proliferation of preadipocytes & $\begin{array}{l}\uparrow \text { Greater effects in preadipocytes isolated from SAT vs. VAT and } \\
\text { females vs. males }\end{array}$ & $\begin{array}{l}\text { Inconsistent results; no effects at low concentration }{ }^{28} \text { or } \downarrow \text { at high } \\
\text { concentration }{ }^{33}\end{array}$ \\
\hline Adipogenesis & $\begin{array}{l}\text { In vitro, inconsistent results; } \uparrow^{28} \& \downarrow^{30} \\
\text { In vivo } \downarrow^{25,23}\end{array}$ & $\begin{array}{l}\text { In vitro, } \downarrow \text {; effects are greater in preadipocytes from VAT vs. SAT }{ }^{34,35} \\
\text { In vivo } \downarrow^{38,39,40}\end{array}$ \\
\hline \multicolumn{3}{|l|}{ Adipose metabolic function } \\
\hline Lipid uptake and storage & $\downarrow$ Lipogenesis and LPL activity ${ }^{22}$ & $\begin{array}{l}\downarrow \text { Meal fat in VAT }{ }^{51} \text { and abdominal SAT } \\
\text { Inconsistent results; no effect }{ }^{49} \text { or } \downarrow \text { FA storage in femoral }{ }^{53}\end{array}$ \\
\hline Lipolysis & $\uparrow$ Lipolysis $^{22}$ & Inconclusive \\
\hline \multicolumn{3}{|l|}{ Adipose endocrine function } \\
\hline Leptin & $\begin{array}{l}\uparrow \text { Secretion from adipose tissues obtained from females, but not } \\
\text { males }^{57}\end{array}$ & $\downarrow$ Gene expression and secretion ${ }^{58}$ \\
\hline Adiponectin & Inconsistent results ${ }^{60,61}$ & $\downarrow$ Secretion of total and $\mathrm{HMW}^{56}$ \\
\hline
\end{tabular}

SAT, subcutaneous adipose tissue; VAT, visceral adipose tissue; LPL, lipoprotein lipase; FA, fatty acid; HMW, high molecular weight. 
how estrogen and androgen regulate adipose tissue development in vivo. We briefly discuss the results from these studies with focus on depot-dependent effects.

\section{Effects of estrogen on adipose tissue development}

Ovariectomy increases, while estrogen replacement after ovariectomy decreases, fat mass in rodents. ${ }^{21,22}$ Impairment in estrogen signaling through knockout of $\mathrm{ER}^{23}$ also leads to obesity in both male and female mice. Further, decline in serum estrogen levels after menopause is associated with development of visceral obesity ${ }^{24}$ whereas hormone replacement therapy in post-menopausal women reduces abdominal obesity. ${ }^{25}$ These data suggest that estrogen is a negative regulator of fat mass in vivo. 2 -week transdermal estradiol treatment in post-menopausal women increases preadipocyte differentiation in femoral but not in abdominal $\mathrm{fat}^{26}$, indicating depot-specific effects on adipocyte development. A recent study using a mouse model that can track adipogenesis in vivo showed that estrogen is one of the factors that contribute to the sex dependent depot-differences in adipocyte development. ${ }^{27}$ Estrogen has been shown to consistently stimulate preadipocyte proliferation with greater effects in preadipocytes isolated from subcutaneous than intraabodminal depots and female than male adipose tissues ${ }^{28,29}$, indicating depot- and sex-dependent effects of estrogen on the proliferation of preadipocytes. Results from in vitro experiments testing the effects of estrogen on adipocyte differentiation are controversial and both suppression ${ }^{30}$ and enhancement of adipogenesis by estrogen ${ }^{28}$ have been reported. Estrogen can modulate fat mass and metabolism through its actions through the central nervous system $^{31}$ and hence, it is not clear whether estrogen regulates fat mass by directly affecting adipocyte development.

\section{Effects of androgens on adipose tissue development}

Hypogonadism in men is associated with central obesity and increasing testosterone concentration in men leads to reduction in total fat mass ${ }^{32}$, suggesting that androgens are important regulators of fat mass as well as fat distribution in men. Dose dependent effects of androgens on the proliferation of preadipocytes, no effects at low concentration $^{28}$ and inhibitory at high concentrations ${ }^{33}$, are reported. Androgens have been shown to consistently inhibit adipogenesis in multiple cell types including human preadipocytes in vitro ${ }^{34,35}$ and hence, through this mechanism androgens could reduce fat mass. The expression levels of AR mRNA and androgen binding capacity are higher in intraabdominal than subcutaneous depots ${ }^{36,37}$ and androgen-mediated suppression of adipogenesis is more pronounced in preadipocytes isolated from omental than subcutaneous adipose tissues. ${ }^{34,35}$ Through this depot-specific inhibition of adipogenesis, androgens may preferentially reduce VAT. Mixed results are however, reported whether androgen treatment leads to preferential loss of abdominal or visceral adiposity in humans. ${ }^{38-40}$ Duration of treatments and age of subjects vary between studies and further careful studies are needed to reach a conclusion.

While estrogen appears to have beneficial roles in the regulation of body fat and metabolic diseases in males both in rodents ${ }^{41}$ and humans ${ }^{42}$, male sex steroids have opposite effects in females. Women with polycystic ovary syndrome exhibit hyperandrogenism concomitant with abdominal and visceral obesity. ${ }^{43,44}$ In addition, treatment with an anabolic steroid with weak androgenic activity leads to visceral fat accumulation whereas treatment with an anti-androgen results in significant less subcutaneous fat loss in obese postmenopausal women. ${ }^{45}$ Studies from rodent models also support that androgens have sex-dependent actions with unfavorable effects in females. Single pulse of testosterone given to female mice within $24 \mathrm{hr}$ postnatal periods results in greater body weight and fat mass that are sustained throughout adult life ${ }^{46}$, suggesting that testosterone-mediated epigenetic programing during early life may lead to development of obesity in female mice in their later life. Further studies are needed to elucidate the mechanisms through which androgens regulate adiposity and metabolic diseases differentially between males and females.

\section{Sex-differences in adipose tissue function}

Adipose tissue is highly active metabolic and endocrine organ. Adipocytes store excess energy as neutral lipid and release it as nonesterified fatty acids (FAs) and glycerol when body demands increase during starvation or exercise. Adipose tissue also secretes numerous peptide hormones, cytokines and bioactive metabolites, that are collectively called as adipokines. Sex differences in adipose metabolic and endocrine functions are beginning to be elucidated and thought to contribute to the sex-dependent differences in fat distribution as well as risks for developing cardiometabolic diseases. 


\section{Sex-differences in adipose lipid metabolism}

The net increases or decreases in adipocyte size and hence, fat mass is determined by the balance between uptake and storage of FAs into triacylglycerol (TAG) and breakdown of TAG and release through lipolysis. To address the mechanisms underlying sex differences in body fat distribution, Jensen's group measured in vivo lipid kinetics. Their studies showed that lower body fat has lower rates of lipolytic rates than upper body per unit mass of tissue in both sexes and women have higher rates of FA release from abdominal subcutaneous than men (Fig. 1). ${ }^{47}$ Meal fat uptake is reported to be greater in lower body vs. upper body fat of lower-body obese women, while they are similar between the two depots of upper-body obese women and men. ${ }^{48}$ Others show that meal FA uptake is greater in upper body than lower body SAT in both sexes. ${ }^{49,50}$ These findings indicate that the meal fat storage may not explain sex-dependent body fat distribution. In women, however, the majority of FA is taken into subcutaneous fat, while in men, a significant portion is taken into visceral fat ${ }^{50}$, consistent with the fact that men storing fat more in visceral depots while females storing more in subcutaneous regions. Direct FA uptake is also greater in abdominal than femoral SAT in men, while it is higher in femoral than abdominal depot of women. Thus, direct FA uptake and possibly meal uptake rather than lipolytic rates may explain sex-dependent body fat distribution.

Estrogen deficiency in women resulted in a $10-20 \%$ increase in lipolysis whereas estrogen repletion does not affect adrenergic stimulated lipolysis. ${ }^{47}$ Estrogen treatment in ovariectomized mice inhibits lipogenesis and increases adipocyte lipolysis, which in results leads to the reduction in adipocyte size..$^{22}$ Estrogen is also a potent suppressor of lipoprotein lipase (LPL) gene transcription. These results suggest that estrogen may decrease fat mass by reducing lipid accumulation. Whether estrogen plays a role in meal fat or direct FA uptake is not known.

The effects of testosterone on lipolytic rates have been inconclusive and reduction in abdominal subcutaneous and visceral lipolysis as well as no effects are reported. ${ }^{47}$ Testosterone treatment decreases meal fat incorporation into TAG in VAT preferentially ${ }^{51}$ and suppresses meal fat uptake into abdominal without affecting in femoral depots. ${ }^{49}$ These studies provide evidence that testosterone may preferentially decreases TAG storage in central depots, which could explain age-associated development of central adiposity in men. However, conflicting results are also reported. Testosterone supplementation for 2 years in elderly men increases meal fat storage into upper- vs. lower-body fat. ${ }^{52}$ In addition, acute testosterone deficiency results in greater femoral adipose tissue meal FA storage rates, LPL activity, and acyl-CoA synthetase activity, indicating that testosterone plays a tonic role in restraining FA storage in femoral adipose tissue. ${ }^{53}$

\section{Sex differences in adipose endocrine function}

Adipose tissue secrets multiple bioactive molecules. Several factors including leptin and adiponectin are derived from adipocytes while others especially proinflammatory cytokines are produced from mainly non-adipocytes present within stromal vascular fraction. We will discuss the two major adipokines, leptin and adiponectin, of which serum levels are known to be higher in women than men.

\section{Sex differences in leptin levels}

Leptin is an endocrine hormone that regulates multiple aspects of physiology including energy homeostasis and immunity. Serum levels of leptin is higher in women than men and these sex differences in serum leptin levels begin even before birth, become more pronounced at later stages of sexual development and persist throughout life. ${ }^{54}$ Sex difference is not due to the fact that women have higher amount of fat mass and women have higher leptin levels even after correcting differences in fat mass. Rather, sex steroid hormones appear to be important determinants of sexual dimorphism in leptin levels. In boys, testosterone levels are negatively correlated, while in girls, estradiol levels are positively correlated with serum leptin levels. Further, leptin concentrations in postmenopausal women are lower than in premenopausal women. ${ }^{55,56}$ These data indicate that positive regulation by estrogen and negative regulation by androgens. Corroborating evidence has been obtained in in vitro studies using adipocyte culture models. Estrogen increases leptin secretion from adipose tissues from females but not those from males. ${ }^{57}$ Conversely, both testosterone and dihydrotestosterone decrease leptin gene expression and secretion from human adipocytes. ${ }^{58}$ Physiological significance of women having higher serum leptin levels is not known. 


\section{Sex differences in adiponectin levels}

Adiponectin is an anti-inflammatory adipokine and known to improve insulin sensitivity by suppressing hepatic glucose production and enhancing fatty acid oxidation in the liver and skeletal muscles. Men have lower adiponectin levels than BMI and age matched women. ${ }^{56}$ Sexual dimorphism in circulating adiponectin levels develops during pubertal development in association with androgen levels ${ }^{59}$, indicating sex steroids regulation of adiponectin levels. Castration increases adiponectin levels and testosterone supplementation lowers serum adiponectin levels. ${ }^{56}$ Men with hypogonadism have significantly higher serum levels of total adiponectin, which are reduced after testosterone replacement therapy. ${ }^{60}$ In addition, testosterone decreases adiponectin secretion in cell culture models. ${ }^{56}$ Controversial results are reported from ovariectomy and estrogen treatment on adiponectin levels both in vivo and in vitro. ${ }^{60,61}$ Thus, low adiponectin levels in men vs. women appear to be predominantly mediated by male sex steroid hormones.

Adiponectin circulates as several oligomeric complexes, high, medium and low molecular weight forms and the ratio of high molecular weight (HMW) forms to total adiponectin are critical in determining insulin sensitivity and cardiovascular diseases. Sex differences in serum adiponectin are mainly due to the differences in its HMW form while the other two forms are not different. ${ }^{60}$ This sexual dimorphism in HMW form of adiponectin is also mediated by androgens as testosterone selectively reduces the circulating levels of HMW adiponectin by inhibiting its secretion from adipocytes, while estrogen has no effect. ${ }^{56}$ Selective reduction of HMW adiponectin in addition to total adiponectin by androgens might be one of the mechanisms that contribute to the higher risk of cardiometabolic diseases in males.

\section{CONCLUSION}

Women and men differ in their fatness and fat distribution pattern. Women contain higher total fat mass, less visceral fat, and lower-body fat accumulation that can explain a significant portion of sexual dimorphism in cardiometabolic risks. Preferential fat accumulation in lower-body depot of women is thought to be explained by higher rate of direct meal fat uptake and FA uptake. In addition, available data suggest that subcutaneous vs. visceral and lower-body vs. upper-body depots particularly in females expand preferentially through hyperplasia, which is considered to be healthier. It is well known that sex steroids are important regulators of adipose biology, both adipocyte development and function, although molecular details of their actions are not completely elucidated. Estrogen appears to be a negative regulator of adiposity in vivo which may be explained in part by estrogen-mediated lipid accumulation. Androgens are known to suppress adipogenesis and lipid accumulation in men and preferential reduction in visceral depots by androgen treatment in men are noted. Disparities in serum levels of the two major adipokines, leptin and adiponectin, also exist. Women have higher levels of leptin and adiponectin and these sexual dimorphisms are known to be mediated by sex steroid hormones. Further studies of sex-dependent depot differences in adipose biology and their relation to systemic health in humans are needed.

\section{CONFLICTS OF INTEREST}

The authors declare no conflict of interest.

\section{REFERENCES}

1. Lee MJ, Wu Y, Fried SK. Adipose tissue heterogeneity: implication of depot differences in adipose tissue for obesity complications. Mol Aspects Med 2013;34:1-11.

2. Yoneshiro T, Saito M. Activation and recruitment of brown adipose tissue as anti-obesity regimens in humans. Ann Med 2015;47:133-41.

3. Geer EB, Shen W. Gender differences in insulin resistance, body composition, and energy balance. Gend Med 2009;6 Suppl 1:60-75.

4. Rebuffé-Scrive M, Enk L, Crona N, Lönnroth P, Abrahamsson $\mathrm{L}$, Smith U, et al. Fat cell metabolism in different regions in women. Effect of menstrual cycle, pregnancy, and lactation. J Clin Invest 1985;75:1973-6.

5. Lemieux S, Prud'homme D, Bouchard C, Tremblay A, Després JP. Sex differences in the relation of visceral adipose tissue accumulation to total body fatness. Am J Clin Nutr 1993; 58:463-7.

6. Au-Yong IT, Thorn N, Ganatra R, Perkins AC, Symonds ME. 
Brown adipose tissue and seasonal variation in humans. Diabetes 2009;58:2583-7.

7. Nookaew I, Svensson PA, Jacobson P, Jernås M, Taube M, Larsson I, et al. Adipose tissue resting energy expenditure and expression of genes involved in mitochondrial function are higher in women than in men. J Clin Endocrinol Metab 2013; 98:E370-8.

8. van den Beukel JC, Grefhorst A, Hoogduijn MJ, Steenbergen J, Mastroberardino PG, Dor FJ, et al. Women have more potential to induce browning of perirenal adipose tissue than men. Obesity (Silver Spring) 2015;23:1671-9.

9. Medrikova D, Jilkova ZM, Bardova K, Janovska P, Rossmeisl M, Kopecky J. Sex differences during the course of diet-induced obesity in mice: adipose tissue expandability and glycemic control. Int J Obes (Lond) 2012;36:262-72.

10. Wu Y, Lee MJ, Ido Y, Fried SK. High-fat diet-induced obesity regulates MMP3 to modulate depot- and sex-dependent adipose expansion in C57BL/6J mice. Am J Physiol Endocrinol Metab 2017;312:E58-71.

11. Drolet R, Richard C, Sniderman AD, Mailloux J, Fortier M, Huot C, et al. Hypertrophy and hyperplasia of abdominal adipose tissues in women. Int J Obes (Lond) 2008;32:283-91.

12. Tchkonia T, Tchoukalova YD, Giorgadze N, Pirtskhalava T, Karagiannides I, Forse RA, et al. Abundance of two human preadipocyte subtypes with distinct capacities for replication, adipogenesis, and apoptosis varies among fat depots. Am J Physiol Endocrinol Metab 2005;288:E267-77.

13. Cancello R, Tordjman J, Poitou C, Guilhem G, Bouillot JL, Hugol D, et al. Increased infiltration of macrophages in omental adipose tissue is associated with marked hepatic lesions in morbid human obesity. Diabetes 2006;55:1554-61.

14. Harman-Boehm I, Blüher M, Redel H, Sion-Vardy N, Ovadia S, Avinoach E, et al. Macrophage infiltration into omental versus subcutaneous fat across different populations: effect of regional adiposity and the comorbidities of obesity. J Clin Endocrinol Metab 2007;92:2240-7.

15. Tchoukalova YD, Koutsari C, Karpyak MV, Votruba SB, Wendland E, Jensen MD. Subcutaneous adipocyte size and body fat distribution. Am J Clin Nutr 2008;87:56-63.

16. Andersson DP, Arner E, Hogling DE, Rydén M, Arner P. Ab- dominal subcutaneous adipose tissue cellularity in men and women. Int J Obes (Lond) 2017 Jun 20 [Epub]. https://doi. org/10.1038/ijo.2017.148

17. Tchoukalova YD, Koutsari C, Votruba SB, Tchkonia T, Giorgadze N, Thomou T, et al. Sex- and depot-dependent differences in adipogenesis in normal-weight humans. Obesity (Silver Spring) 2010;18:1875-80.

18. White UA, Fitch MD, Beyl RA, Hellerstein MK, Ravussin E. Differences in in vivo cellular kinetics in abdominal and femoral subcutaneous adipose tissue in women. Diabetes 2016;65: 1642-7.

19. Tchoukalova YD, Votruba SB, Tchkonia T, Giorgadze N, Kirkland JL, Jensen MD. Regional differences in cellular mechanisms of adipose tissue gain with overfeeding. Proc Natl Acad Sci U S A 2010;107:18226-31.

20. Chen X, McClusky R, Itoh Y, Reue K, Arnold AP. X and Y chromosome complement influence adiposity and metabolism in mice. Endocrinology 2013; 154:1092-104.

21. Lindberg MK, Weihua Z, Andersson N, Movérare S, Gao H, Vidal O, et al. Estrogen receptor specificity for the effects of estrogen in ovariectomized mice. J Endocrinol 2002;174:16778.

22. D’Eon TM, Souza SC, Aronovitz M, Obin MS, Fried SK, Greenberg AS. Estrogen regulation of adiposity and fuel partitioning. Evidence of genomic and non-genomic regulation of lipogenic and oxidative pathways. J Biol Chem 2005;280: 35983-91.

23. Heine PA, Taylor JA, Iwamoto GA, Lubahn DB, Cooke PS. Increased adipose tissue in male and female estrogen receptoralpha knockout mice. Proc Natl Acad Sci U S A 2000;97: 12729-34.

24. Lovejoy JC, Champagne CM, de Jonge L, Xie H, Smith SR. Increased visceral fat and decreased energy expenditure during the menopausal transition. Int J Obes (Lond) 2008;32:949-58.

25. Salpeter SR, Walsh JM, Ormiston TM, Greyber E, Buckley NS, Salpeter EE. Meta-analysis: effect of hormone-replacement therapy on components of the metabolic syndrome in postmenopausal women. Diabetes Obes Metab 2006;8:538-54.

26. Cox-York KA, Erickson CB, Pereira RI, Bessesen DH, Van Pelt RE. Region-specific effects of oestradiol on adipose-derived 
stem cell differentiation in post-menopausal women. J Cell Mol Med 2017;21:677-84.

27.Jeffery E, Wing A, Holtrup B, Sebo Z, Kaplan JL, Saavedra-Pena $\mathrm{R}$, et al. The adipose tissue microenvironment regulates depot-specific adipogenesis in obesity. Cell Metab 2016;24:14250.

28. Dieudonne MN, Pecquery R, Leneveu MC, Giudicelli Y. Opposite effects of androgens and estrogens on adipogenesis in rat preadipocytes: evidence for sex and site-related specificities and possible involvement of insulin-like growth factor 1 receptor and peroxisome proliferator-activated receptor gamma2. Endocrinology 2000;141:649-56.

29. Anderson LA, McTernan PG, Barnett AH, Kumar S. The effects of androgens and estrogens on preadipocyte proliferation in human adipose tissue: influence of gender and site. J Clin Endocrinol Metab 2001;86:5045-51.

30. Ihunnah CA, Wada T, Philips BJ, Ravuri SK, Gibbs RB, Kirisci L, et al. Estrogen sulfotransferase/SULT1E1 promotes human adipogenesis. Mol Cell Biol 2014;34:1682-94.

31. Mauvais-Jarvis F, Clegg DJ, Hevener AL. The role of estrogens in control of energy balance and glucose homeostasis. Endocr Rev 2013;34:309-38.

32. De Maddalena C, Vodo S, Petroni A, Aloisi AM. Impact of testosterone on body fat composition. J Cell Physiol 2012;227: 3744-8.

33. Fujioka K, Kajita K, Wu Z, Hanamoto T, Ikeda T, Mori I, et al. Dehydroepiandrosterone reduces preadipocyte proliferation via androgen receptor. Am J Physiol Endocrinol Metab 2012; 302:E694-704.

34. Rice SP, Zhang L, Grennan-Jones F, Agarwal N, Lewis MD, Rees DA, et al. Dehydroepiandrosterone (DHEA) treatment in vitro inhibits adipogenesis in human omental but not subcutaneous adipose tissue. Mol Cell Endocrinol 2010;320:51-7. 35. Gupta V, Bhasin S, Guo W, Singh R, Miki R, Chauhan P, et al. Effects of dihydrotestosterone on differentiation and proliferation of human mesenchymal stem cells and preadipocytes. Mol Cell Endocrinol 2008;296:32-40.

36. Dieudonne MN, Pecquery R, Boumediene A, Leneveu MC, Giudicelli $Y$. Androgen receptors in human preadipocytes and adipocytes: regional specificities and regulation by sex steroids.
Am J Physiol 1998;274:C1645-52.

37.Joyner J, Hutley L, Cameron D. Intrinsic regional differences in androgen receptors and dihydrotestosterone metabolism in human preadipocytes. Horm Metab Res 2002;34:223-8.

38. Mårin P, Holmäng S, Jönsson L, Sjöström L, Kvist H, Holm G, et al. The effects of testosterone treatment on body composition and metabolism in middle-aged obese men. Int J Obes Relat Metab Disord 1992;16:991-7.

39. Allan CA, Strauss BJ, Burger HG, Forbes EA, McLachlan RI. Testosterone therapy prevents gain in visceral adipose tissue and loss of skeletal muscle in nonobese aging men. J Clin Endocrinol Metab 2008;93:139-46.

40. Münzer T, Harman SM, Hees P, Shapiro E, Christmas C, Bellantoni MF, et al. Effects of GH and/or sex steroid administration on abdominal subcutaneous and visceral fat in healthy aged women and men. J Clin Endocrinol Metab 2001;86:360410.

41. Dakin RS, Walker BR, Seckl JR, Hadoke PW, Drake AJ. Estrogens protect male mice from obesity complications and influence glucocorticoid metabolism. Int J Obes (Lond) 2015;39: 1539-47.

42. Cheng KH, Huang SP, Huang CN, Lee YC, Chu CS, Chang $\mathrm{CF}$, et al. The impact of estradiol and 1,25(OH)2D3 on metabolic syndrome in middle-aged Taiwanese males. PLoS One 2013;8:e60295.

43. Lim SS, Davies MJ, Norman RJ, Moran LJ. Overweight, obesity and central obesity in women with polycystic ovary syndrome: a systematic review and meta-analysis. Hum Reprod Update 2012;18:618-37.

44. Dumesic DA, Akopians AL, Madrigal VK, Ramirez E, Margolis DJ, Sarma MK, et al. Hyperandrogenism accompanies increased intra-abdominal fat storage in normal weight polycystic ovary syndrome women. J Clin Endocrinol Metab 2016; 101:4178-88.

45. Lovejoy JC, Bray GA, Bourgeois MO, Macchiavelli R, Rood JC, Greeson C, et al. Exogenous androgens influence body composition and regional body fat distribution in obese postmenopausal women--a clinical research center study. J Clin Endocrinol Metab 1996;81:2198-203.

46. Jang H, Bhasin S, Guarneri T, Serra C, Schneider M, Lee MJ, et 
al. The effects of a single developmentally entrained pulse of testosterone in female neonatal mice on reproductive and metabolic functions in adult life. Endocrinology 2015;156:3737-46.

47. Santosa S, Jensen MD. Sex and sex steroids: impact on the kinetics of fatty acids underlying body shape. Horm Mol Biol Clin Investig 2014;20:15-23.

48. Koutsari C, Ali AH, Mundi MS, Jensen MD. Storage of circulating free fatty acid in adipose tissue of postabsorptive humans: quantitative measures and implications for body fat distribution. Diabetes 2011;60:2032-40.

49. Mårin P, Odén B, Björntorp P. Assimilation and mobilization of triglycerides in subcutaneous abdominal and femoral adipose tissue in vivo in men: effects of androgens. J Clin Endocrinol Metab 1995;80:239-43.

50. Romanski SA, Nelson RM, Jensen MD. Meal fatty acid uptake in adipose tissue: gender effects in nonobese humans. Am J Physiol Endocrinol Metab 2000;279:E455-62.

51. Mårin P, Lönn L, Andersson B, Odén B, Olbe L, Bengtsson BA, et al. Assimilation of triglycerides in subcutaneous and intraabdominal adipose tissues in vivo in men: effects of testosterone. J Clin Endocrinol Metab 1996;81:1018-22.

52. Koutsari C, Ali AH, Nair KS, Rizza RA, O’Brien P, Khosla S, et al. Fatty acid metabolism in the elderly: effects of dehydroepiandrosterone and testosterone replacement in hormonally deficient men and women. J Clin Endocrinol Metab 2009;94: 3414-23.

53. Santosa S, Bush NC, Jensen MD. Acute testosterone deficiency alters adipose tissue fatty acid storage. J Clin Endocrinol Metab 2017;102:3056-64.

54. Alexe DM, Syridou G, Petridou ET. Determinants of early life leptin levels and later life degenerative outcomes. Clin Med
Res 2006;4:326-35.

55. Rosenbaum M, Nicolson M, Hirsch J, Heymsfield SB, Gallagher D, Chu F, et al. Effects of gender, body composition, and menopause on plasma concentrations of leptin. J Clin Endocrinol Metab 1996;81:3424-7.

56. Nishizawa H, Shimomura I, Kishida K, Maeda N, Kuriyama H, Nagaretani H, et al. Androgens decrease plasma adiponectin, an insulin-sensitizing adipocyte-derived protein. Diabetes 2002;51:2734-41.

57. Casabiell X, Piñeiro V, Peino R, Lage M, Camiña J, Gallego R, et al. Gender differences in both spontaneous and stimulated leptin secretion by human omental adipose tissue in vitro: dexamethasone and estradiol stimulate leptin release in women, but not in men. J Clin Endocrinol Metab 1998;83:2149-55.

58. Wabitsch M, Blum WF, Muche R, Braun M, Hube F, Rascher $\mathrm{W}$, et al. Contribution of androgens to the gender difference in leptin production in obese children and adolescents. J Clin Invest 1997; 100:808-13.

59. Böttner A, Kratzsch J, Müller G, Kapellen TM, Blüher S, Keller E, et al. Gender differences of adiponectin levels develop during the progression of puberty and are related to serum androgen levels. J Clin Endocrinol Metab 2004;89:4053-61.

60. Xu A, Chan KW, Hoo RL, Wang Y, Tan KC, Zhang J, et al. Testosterone selectively reduces the high molecular weight form of adiponectin by inhibiting its secretion from adipocytes. J Biol Chem 2005;280:18073-80.

61. Combs TP, Berg AH, Rajala MW, Klebanov S, Iyengar P, Jimenez-Chillaron JC, et al. Sexual differentiation, pregnancy, calorie restriction, and aging affect the adipocyte-specific secretory protein adiponectin. Diabetes 2003;52:268-76. 